\title{
La pintura histórica
}

\section{The historical painting}

U n género muy particular de la pintura es aquel que relata o representa una historia. Durante el renacimiento, el neoclasicismo y el romanticismo es cuando encontramos las obras más importantes, en las que se representaban historias bíblicas o de la antigüedad, así como leyendas de la mitología. Posteriormente fueron los hechos históricos los más recurrentes. Las obras tenían por objeto resaltar algún valor moral de la situación o de sus personajes y debido a su gran formato, servían para la decoración de espacios públicos, palacios o edificios de gobierno. Por la riqueza de sus detalles, tienen un gran valor educativo, ya que relatan en una sola escena lo que puede ser dicho en mil palabras.

La muerte de Sócrates, obra del pintor francés Jacques-Louis David, es un ejemplo del neoclasicismo; en ella, el filósofo domina la escena, rodeado de sus discípulos. Platón se encuentra a la izquierda, de espaldas al maestro, quién se apresta a tomar la copa de cicuta, luego de pronunciar su discurso sobre la inmortalidad del alma.

La obra El tres de mayo de 1808 en Madrid de Francisco de Goya, es notoriamente realista, y representa el horror de la guerra; en este caso, los fusilamientos de los madrileños sublevados contra Napoleón. El héroe, en el centro, con camisa blanca y los brazos hacia el cielo, contrasta con los tonos oscuros hasta el negro, de la noche y los fusileros.

Otra obra importante del género es La libertad guiando al pueblo, de Eugène Delacroix, pintor francés del romanticismo. Esta es una obra alegórica, en que se representa un valor, en esta caso la libertad, en forma de mujer, evocando a la Atenea griega. La muchedumbre es difusa, apreciándose La Bastilla a la derecha, y el cielo tricolor, como reflejo de la bandera de Francia.

Luego de la declinación del academicismo, parecía que la pintura histórica no vería más íconos; sin embargo en 1937, Pablo Picasso pinta Guernica, una de sus obras maestras, y quizás la última gran obra del género. En ella, junto con el toro, la paloma y el caballo, podemos apreciar a la derecha, al mismo héroe trágico del cuadro de Goya, con los brazos hacia el cielo.

Ernesto Payá Hospital de Carabineros

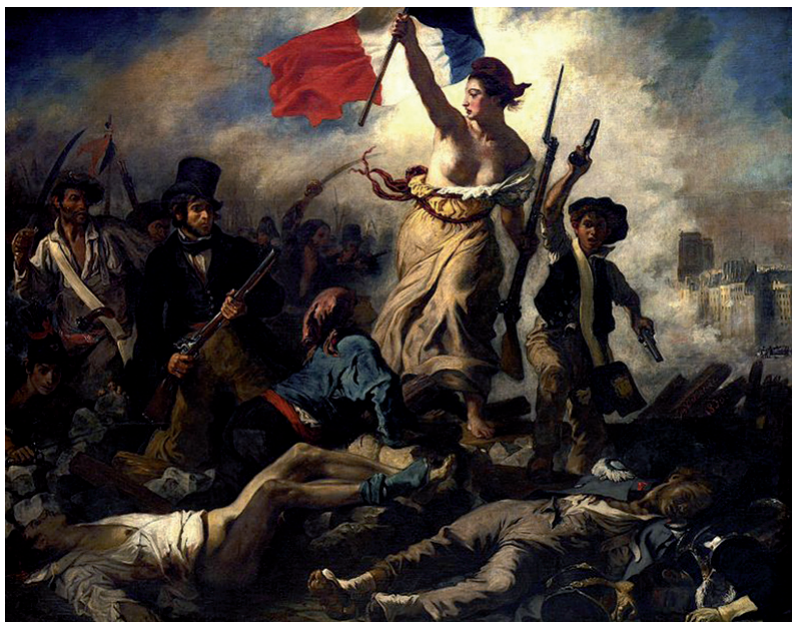

Figura 3. La libertad guiando al pueblo. Eugène Delacroix. 1830. Museo del Louvre. París.
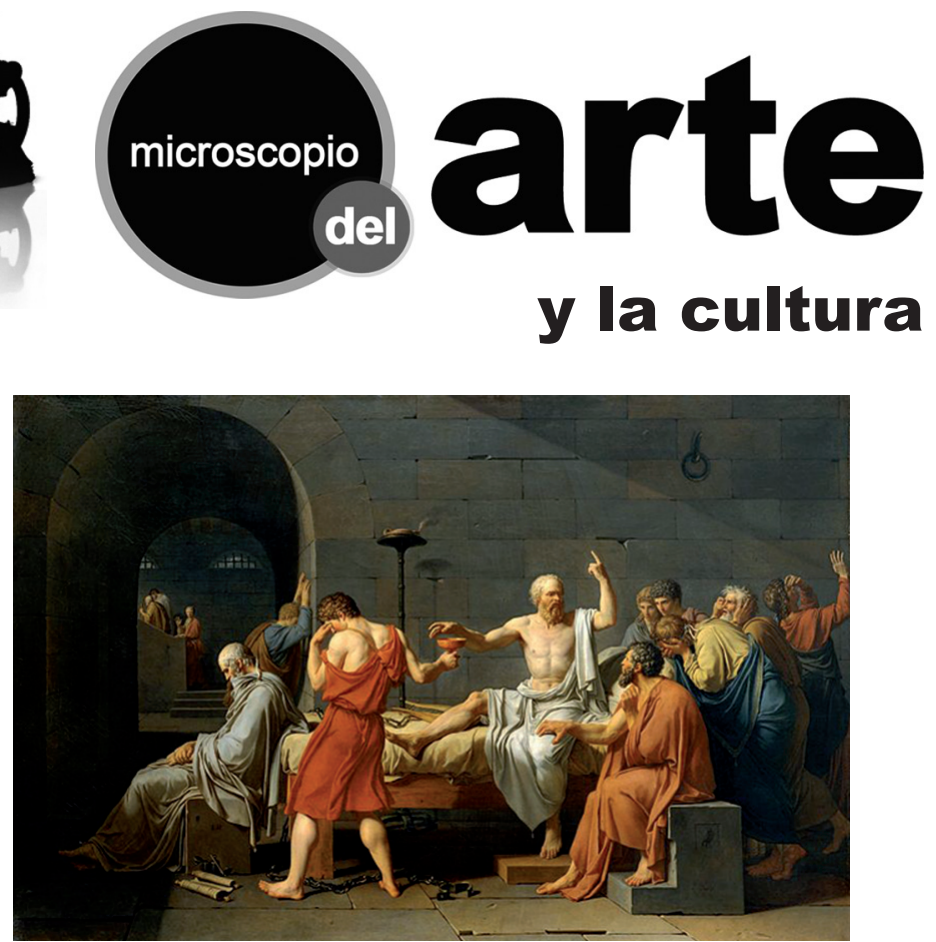

Figura 1. La muerte de Sócrates. Jacques-Louis David. 1787. Museo Metropolitano de Arte, Nueva York.

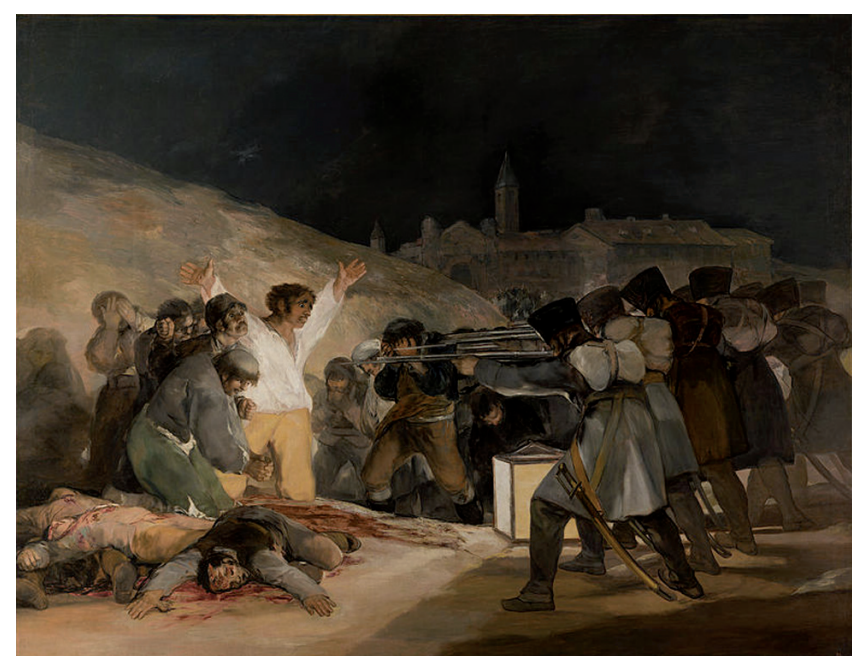

Figura 2. El tres de mayo de 1808 en Madrid. Francisco de Goya y Lucientes. 1814. Museo del Prado, Madrid.

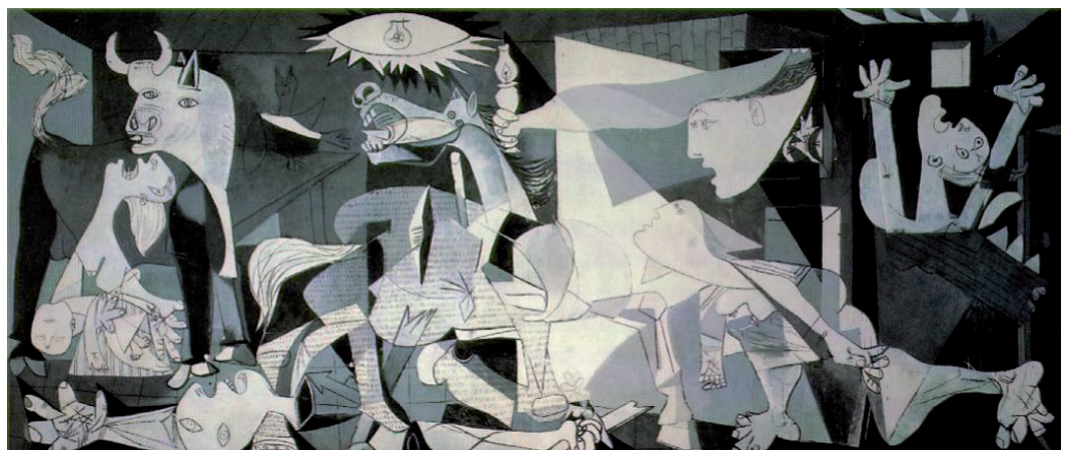

Figura 4. Guernica. Pablo Picasso. 1937. Museo Nacional Centro de Arte Reina Sofía. Madrid. 